\title{
Teacher views of headmasters regarding to fulfilling management functions of human resources
}

\begin{abstract}
The aim of this research is to determine and evaluate teacher views of headmasters regarding to fulfilling management functions of human resources. A conceptional frame is provided regarding to importance of human resources at educational institutions and for the definition of human resources primarily. In the research, sufficiency of headmasters regarding teacher views on fulfilling functions of human resources were discussed as: a) Management problems b) socio-economic problems c) what kind of management is indigenised by headmasters. In the research, a qualitative research was conducted which views of teachers are taken, semi-structured data collection model was used which is based on open-ended questions and views of experts were included. The environment of the research is the teachers who are on duty at a private school in the T.R.N.C. In the frame of the research, three questions which were prepared before was used and a way of research which is conducted as interview method was used. Presentment method was used at analyse of the data.
\end{abstract}

At the result of the research, carelessness about authoritarian problem, not being fair at the distribution of tasks, disobeying the hierarchic order, the situation that existing problems are not solving by share of information, the situation that headmaster is not insistent and participant without inspecting teachers, desire of headmaster to move on his or her own at the problems which are in school or which will occur, are among the problems at the human resources management. Within the lights of obtained data, it is seen that the motivation and performance of teachers are affected by verbal communication ways of headmasters and views of teachers against headmasters are at same topics and in this content, it is expected from headmasters to inspect teachers and perform roles like finance, budget and making decisions. It is seen that, differentiates will be created by headmasters on teachers in the content of conducting human resources management. The situation that headmaster are more prescient and researcher with the management of human resources and to function of human resources by evaluating the functions and management of human resources in content of creating better communication and management environment, will provide an insight to implementation and development of deficiencies due to the situation that this will be effective to divergences. It is seen that, motivation of teachers who work in the education institution is low due to high expectations and due to this situation there would be separation between teachers and there will be challenges at information transmission due to situation that teachers consider themselves as inadequate, originating from headmaster who cannot fulfil the functions of $m$ human resources management completely while carrying out the research.

In education, the management of human resources is difficult, individual importance is very important and the effectiveness and productivity of an educator is role of headmaster, however the educator who has self-trust should be in effort to manage the people with physical and emotional ways, should have a structure to put the motivation high and help to the success of teachers and should prevent the organization between educators. In education, to reach high success by getting rid of the standards and to pull out the education from the concept of need the situation that a common view with teachers should be provided, educator should direct himself or herself to aims so should collect sources for school, should provide a positive environment to the expectations of students and society, should go for aim by taking views from teachers at decision progress and there should be situation provided that headmasters take faster decisions and that headmasters have good communications with teachers with the aim of not interrupting the education.

Keywords: human resources, school headmasters
Volume 2 Issue I - 2018

\author{
Mustafa Behlül, Çağda Kıvanç Çağanağa \\ Department of Pre School Education, European University of \\ Lefke, Turkey
}

Correspondence: Çağda Kıvanç Çağanağa, Department of Pre School Education, European University of Lefke, Institute of Graduate Studies and Research, Turkey, Tel 05488360236 , Email ckivanc@eul.edu.tr

Received: November 14, 2017 | Published: January 12, 2018

\section{Introduction}

In this research, it is aimed to provide the situation that school headmasters can reach to personnel in more effective and efficient way and the situation that school headmasters can understand the views and problems of headmasters and teachers with the aim of providing co-operation by putting forth the views of headmasters upon teachers at fulfilling the functions of human resources management. School headmasters are seen as individual who protects the purpose, structure and environment of school and who is a precursor at carrying the 
school into one step forward. Modern headmasters are the individuals who have a good leadership qualities, who are extensive, who have communication and management skills, who have a good usage of mother language, who know foreign languages, who manages the information, who have taken philosophy, mathematics and civilization history and who believe in education. ${ }^{1}$ The situation that school headmasters have provided a good communication and management environment of human resources management and functions, have created data. An insight will be provided to the progression of and implementation of deficiencies without deficiency at management of human resources and functions by conducting realistic evaluations and by approaching to the problems at management of human resources and functions and by hoping that new research field will occur.

The role of headmasters is very significant at the activity and efficiency of education institutions and at the institutions which social and individual importance very significant without discussion. The daily problems and duties of headmasters have started to be different with the situation that education institutions have more complex structures while previously the duties of headmasters were just managing teachers. The differences at the responsibility and duty understandings due to existing modern change provided the adoption of new management understandings by headmasters by getting rid of the old modern management approaches. School headmasters are not only interested in education processes however the responsibility is taken by headmasters and an education programme is created by headmasters with the aim of creating an effective school. School headmasters must have a strong information base and vision. A more detailed explanation was made by Smith and Andrews (1989) and the situation that managers who show a strong leadership should have the qualities are determined below. ${ }^{2}$

i. Determination of primarily topics at the program and education.

ii. Self-commitment to purposes of school.

iii. Collecting and mobilizing resources for purposes of school

iv. Providing a positive school environment which will meet high expectations of society, teacher, parent and student.

v. Developing the teaching policy of the school

vi. To follow the progression situation and teacher activity with the purpose of improving the success of the school

vii. To show that headmaster is royal to academic purposes of school, to determine long term school purposes and implement purposes

viii. To take the views of groups and related units actively at the decision process of the school

ix. Usage of time effectively and efficiently and providing the reach to academic success more actively

$\mathrm{x}$. To realise that time is a insufficient source and to create a discipline and order to degrade the factors that will interrupt the time of education.

School headmaster should use the management and function of human resources in the best way with the aim of helping to the school to reach aims of school in the most effective way. The management of human resources have a sufficient importance for headmasters in this process and the management of human resources will contribute to solve problems effectively which occur in the education institutions and will also contribute to advance in a more effective way.

\section{The definition of the human resources management}

A. The human resources management is the name given to the section whose aim is to meet needed human power and to arrange the communication between employee and taskmaster in the workplace. The section which just prepared dockets before is nowadays interested in works that is related with employees like industrial, syndicate works, management of profession, recruitment, dismissal, satisfaction of employees, social and administrative services and institutional performance by taking the name human resources management. Human resources is one of the most important assets of the organization because of its efforts to achieve its goals, to gain competitive advantage and to meet the expectations of environmental elements. ${ }^{3}$ The management of human resources can be defined as a whole of functions and employees that, provides active management of human resources as beneficial to individual and environment by obeying the laws.

B. The management of human resources is considered as the most valuable presence of an institution with the broadest concept so the management of human resources can be defined as, a consistent and strategic approach which is developed with the aim of managing an institution efficiently. human resource management is a concept that is often used to describe the philosophy, policies, methods and practices of people who work in an organization. ${ }^{4}$ The management of human resources is a section which includes financial and judicial relationship between management of employee, taskmaster, institution and government and the field of human resources management is the most sufficient work field. The management of human resources field involves, determination of needs of employee, suitable selection of employee, realising the employee announcements, performance evaluation, the solving of arguments in the office, improving the relationship between management and employee, providing a healthy institution, providing the situation that employees are educated and developed and to develop the emotion of "us". 5

\section{Problems that emphasize the management of human resources}

Efficiency: The material in the business which is used at production, defines the human power, fund, energy, riches and service. If a business can produce much product and much service and perform so much with the least material, human power and with the least riches, that means that the efficiency in the business is very high. ${ }^{1}$

Changes: The first of factors that emphasize the management of human resources are the changes that occur in present day. The life is affected by these changes in the field of cultural, judicial, educational, social and technological fields. The change of individuals is caused by these changes by affecting believes, expectations and values of individuals.

\section{The symptoms of negativeness at the workplace}

The negativeness is caused by lack of motivation, absenteeism, the transfer of work power, and by behaviours against efficient work production. The management of human resources, that tries to search 
the reasons and find solutions to these behaviours that is boredom of work, dissatisfaction and estrangement, have a big role.

Globalization: The globalization means, more competition and problems in terms of ownership and the share, activities and production of market share with the expansion of market share.

\section{The importance and management of human resources management in educational institutions}

The management of human resources form a basis for common purposes and latent values which will provide the durability of institution. The royalty of institution provides the share of the culture. The management of human resources can be implemented effectively in the education institutions. The reason of this is the situation that, organisational culture of the school is suitable with the approach of the human resources management. The management of human resources is tried to be improved by school administration. Human is the treated and worker source in this field. The management of human resources is implemented successfully if a school believes that the human resources are the most valuable source and if that school values people. ${ }^{6}$ Teachers are the most valuable sources in the school who use the human resources in the best way. Education managers manage the treated and worker human source. Education managers in the school are the individuals that, the situation that the environment which students are effective, efficiency and quality studied, are expected from.

The aim of the human resources management is not really differs from other the aims of other organizations as it is understood. The most important difference in school or in education institution is the obligation of groups for to be in education all the time. The new technology marketing techniques which are under development are interested in to education and progress of employees in terms of new sale tracing. However the education of employees in the schools is quite important and absolute valid. There are studies being performed about programs for students in education fields due to the situation that there are students who have different intelligence type. The situation that teachers should reach to students with the new technology and with the new techniques is obligatory. Due to this situation, schools that are in the obligatory for competition have to perform studies with the aim of complying with the technology. The biggest difference of schools when compared with other studies is the situation that school need the human resources more due to the situation that input and output of school are human beings. With the situation that relationships are healthy, relationships have to be at the position that are connected to absence and activity of the human resources, due to the situation that, there are always human beings in the education studies. There is a necessity that, the personnel of human resources should have a big effect on school personnel and students.

\section{The purpose of human resources management at the education institutions}

Everyone in the school without considering position, unit and priority, are connected to the unit of the human resources management. The management of human resources management is interested with the employing people, retiring people, the situation that retired people have important roles and implements and develop modern techniques at the active and efficient work of the people. There are two basis purposes of the human resources management. The first purpose is to, maximize the contribute of employee in the institution by taking the efficient and proper usage of skill, ability and information of people and the second purpose is to provide the job satisfaction of people who work in the institution. ${ }^{7}$ Education institutions should make a human power plan with the purpose of performing these activities. Institution managers face with the difficulties when, they cannot perform this activities and also face with difficulties at employing people to defficient units. There is a necessity to the situation that there is a expert team at the human resources management in institutions due to this situation.

The purpose of the human resources management in the education institutions can be explained like this, employees and managers should be in compliance to provide the situation that the institution meet the aims successfully. Other purpose of the human resources management are to, determine the righths and responsibilty of employee, determine the wage policy by determination of performance, and to perform educations with the reason of increasing work effiency of employee and increasing the effiency of education and profession plans. However, the best way to meet the aims is to consider the aims. Other purposes of the human resources management is to, provide the situation that employees see their aims of business, that managers and teachers consider the institution as a part of themselves, to plan an efficient organization, to provide the situation that managers and teachers are in a teamwork by increasing the loyality and dependence in the school, to provide the situation that, human resources management is chosen as efficient, effective and correct and to determine the education needs of managers and teachers and to perform the control of these needs. ${ }^{8}$ The situation that the efficiency and quality of teachers and managers will be increased, future aims of institution which will bring skillfull individuals to future years will be provided and active communucation system will be provided among employees, will be provided through these educations. Education institutions which prominence the apprehension about the purposes of human resources and includes the effects regarding to creation of respect to people have a special structure. Schools present qualified and developed human resources to institutions by taking human resources from every all segments of the society. Schools have a big role at the management of human resources due to the structure of the society, with this reason. ${ }^{9}$

\section{The management and function of human resources in education institutions}

The management of the human resources is performing the process by passing certain phases. The human resources process in the institutions are to plan the future, putting the existing situation forth and to determine the needs. The situation is not so different when the education institutions are considered. This process in the education institutions are performed by the processes of management, recruitment, selection, of wage, management of education and profession and the evaluation of performance.

\section{The planning of human resources in the education institutions}

The planning of human resources is the situation that the institution follow a strategic way to meet the future human resources needs. The situation that institution employ people who have suitable skills to the field that need employee is the planning of the human resources. The human resources planning is a process which, evaluates and organises entry, exit and movement in the institution. The aim of the planning of human resources is to provide the active usage of human resouces. ${ }^{1}$ The planning of the human resources is important at the 
education institutions in regards to successs effect of institution. The changing exam methods and exam directings occurs the need for the development of teachers. Considering the past success of students and realising the future education planning, have big role at creating the instituional image and future successes at education institutions. The purposes of human resources planning are taking the best efficient from human resources and being objective at employing and unemploying people. Basic function of the management are creating the order and to prepare the human resources management against the development at the internal and external environment. ${ }^{10}$

\section{Procurement of human resources at education Institutions}

This is different at other institutions due to the situation that periodicity is aforementioned in the education institutions. The employment of teachers and response time are different in education institutions when compared with other institutions. Education institutions are at the certain periods of the year. Later than there are retirements and quitting jobs at the end of the semester and new teachers are determined by the evaluation of responses. Education institutions take the usage of internal and external sources like the other institutions.

Internal sources: Education institutions take the the least usage from these sources due to the situation that the promotion is very low. The promotion of the teacher means that the teacher is at the position of a manager however, the situation that manager positions are not so much in education institutions decreases this rate. Branch out is not so much at education institutions so the situation that mathematics teacher is placed as a turkish teacher can be given as example.

External sources: The provide of employee from the external sources are very high in terms of creating the pool of candidates. The chance of choosing employee to the necessity profile in the institution increases with the increase of candidates. ${ }^{11}$ There are various ways to search for employee candidates outside the institution. Institutions take the usage of methods like, accepting applications from the internet, advertising from the internet, search for the employee from the profession sites at the internet, making applications to the job institutions, make contact with the successfull employee at the rival company, conducting researches at the profession institutions and evaluating the individuals with the advice of existing employee and the institutions which take the usage of these methods become successful. ${ }^{1}$ Taking the usage of external sources is the most preferred method in the education institutions. The periodicity is aforementioned at the taking usage of external sources at education institutions. Periodicity, coincides with the beginning of summer holiday in the education institutions. This situation have some reasons. It is seen that teacher changes at the schools are at the certain times. The situation that students are input of the education institutions are the reason of this. Employment and unemployment of teachers form a big problem to education institutions due to this situation. It can be seen that the individuals who can work at the education institutions are the teachers and this situation occurs the necessity of contacting teachers at other schools and employing them or contacting new graduates from universities who are wise or qualified for the education institutions. Human resources make employments from existing pools. Other way of employment is the employment which is made by advice. School administration prefers the selection of employee from external sources by taking the advice from internal sources however the confidence is very important. The situation that the rate of mistakes are low is purposed with this way.

\section{The selection of human resources at the education institutions and the management of education}

There are too many methods being used at the employment and unemployment of people at the education institutions. The main purpose of using these methods are to collect information about applications. If the applications that are made are too many, there is a good selection at the same rate. ${ }^{12}$ An analyse in performed about the position which employment is going to be made with the aim of determining main conditions which the employee have to have. The whole of the work and analyse have to be for the work and suitable for the work. The conditions are determined which the employee have to have, with the job agreement. People have great ideals in general manner. However the ideals that they hope to reach are not easy. People have to take usage of information technologies well to reach ideals that they hope for. Institutions which do not use information technologies are not successfull in general manner and cannot compete with the other institutions. ${ }^{13}$

The institution select suitable employee to realise the human resources selection and reach the aims fastly. Consistence of employee at education institutions is very important. If consistence is not valid, problems between teacher, student, manager and parents occur and these problems get bigger and bigger. The consistence of the employee is very important however if the students are uncessfull there will be problems that are unrecorevable. Interviews and questions forefront the charecteristics of employees and use these as criterion. Information about the culture of institution is given to the candidate by determination of these criterion and test and interview forms. The control of the problems that will occur is provided by this way. The education management is the process of using human power sources with the aim of providing the change at the behaviours of people. The education management have three main factors and these are student, teacher and manager. Student is the source that have not reached to the intended level. Teacher is an important source who teach the human resources. Manager is responsible from managing both sources. Education manager is the individual who, provide the best raise of students and teacher is the individual who, provides suitable environment for students to work in the best efficient way and to serve in the best way.

The human resources are the sources that have the most tendency for progression. These sources can be seen as machine, money and material when managers in the institution do not know these sources. This is a very big executive mistake. The most important duty of the education manager is to raise individual who is convenient for the progression according to desires and creating an environment which is suitable and efficient. ${ }^{14}$ The analyse of the employee should be conducted with the aim of determining the necessity of education in schools. The necessity of employee is determined by these analyses and unnecessary education is prevented and the situation that employee take deficient education is provided. The situation that employee is educated at the topic that they know is prevented with the time loss by educating employee at their own defficient topics. There are individual needs, organisation needs and vocational needs at the determination of education needs. ${ }^{1}$

\section{Governance}

Governance expresses the whole of interaction which common and mutual communucation is in the foreground rather than control of institution just by one side. Governance is managing together is 
general manner. It emphasisez the consistent, transparent, participant, responsible, fair, and accountable management activities (www.tasam. org). The shortest and the sharpest definition of the governance is the usage of economic authority in private and official institutions and the usage of authority in administrative institutions. Governance which means together and common, includes the definitions of interaction and communcation different from management.

\section{Governance responsibilities and problems at schools}

The governance of school is used to emphasize the gap which will occur at the systems of education in schools. Individuals manage events which behaviours cannot be predicted and individuals whose behaviours can be predicted manage people. Open and democratic approach is the only way for the success which can be maintained in a quality school due to the situation that headmasters cannot manage much problem and factors (www.edchreturkey-eu-coe.int). The admistration of school develop the student and discipline, increase the competition at the school and secures the future for a maintainable democracy for the democratic management of the school. The role of the school decreases and who is going be responsible at the works is uncertain when the governance system is applied at the school. The governance submits a concrete approach about the situation that the protective behaviour of the school could be changed when moving to governance from management of the school (www.kisi.deu.edu.tr). The thought of school contribution is pushed aside and the approach of the school administration to teachers, students and parents is changed in the means of institutional.

\section{Method}

The model of the research, work group and tool for collecting data is given place at this part of the research. An qualitative research is realised that the views of headmasters for teachers about fulfilling the management and factors of the human resources is received. Semistructured data collection model was used which is based on openended questions. According to,${ }^{15}$ questions will be prepared in the nature of this meeting and for the get more details and explanations more questions will be given place at the end. According to ${ }^{16}$ the method of meeting, meeting is the technique of receiving data by verbal communication way. Meeting is made face to face oftenly however it can be realised by telephone or by voice and image transmitter. The meeting technique which is usually used at the social sciences field has a different place. The basis of meeting technique comes from talking face to face as it can be understood from the name. Meeting which individuals use often at the daily life, should be sustained within the framework of certain rules at the scientific researches. There are two people in the meeting technique, first of them is the researcher and second of them is the source person. Researcher use questions which were prepared before and sustains the research with the source person. The situation that every person answer the questions as sincerely and warmly is believed by taking the usage of the received information and by realising the information taken from the literature is correct. The research is at the 2017-2018 academic year and limited with the region of Nicosia. The answer will be tried to receive to the problems below:

a. What are the problems that school headmasters face when fulfilling the factors of human resources?

b. What are the responsibilities of school headmasters about solving the social and economic problems while fulfilling the factors of human resources? c. What kind of management type is adopted by headmasters at fulfilling the factors of human resources?

The environment of the research is the teachers who are on duty at a private school in the T.R.N.C. The samples of the study are the teachers of English Culture College which is at the region of Nicosia. The views of eight teachers were received in this study. In the frame of the research, three questions which were prepared before was used and a way of research which is conducted as interview method was used. Eight teachers who were selected for the study participated in the study according to their rank of graduation in the school. A qualitative study was conducted and the reason for this method was to expose the teachers 'views. The quality of a scientific research reveals its validity and reliability. Validity and reliability some measures are taken to ensure the validity and reliability of a qualitative research, even though the concepts of validity and reliability have different meanings within the qualitative research tradition. Some of these include: diversification techniques, participant verification, data collection processes and sufficient participation (data saturation), disclosure of researcher's stance (reflective), detailed disclosure of the research trail (audit), sampling for the purpose of "this kind of organization is applied in companies that produce various goods or services and are quite large. The establishment of separate departments for each product to be produced is an appropriate form of structuring making, detailed description.

Presentment method (Scientific overview tool and method, which determine real facts and phenomenon with the help of lingual decribtions) was used at analyse of the data. Eight teaching volunteers participated in the study. In this study, content analysis was made by defining, coding, classifying and labelling themes in the analysis of qualitative data obtained from interviews, and the similarities and differences of interpretations were coded to analyze teacher's views. The main subject of each interview question is the category and the resulting keywords related to each other are grouped into themes under the relevant categories. In order to draw attention to the codes obtained in this process, descriptive analysis technique was used by taking into account the opinions of the participants without any changes. As a result of this process, it was checked whether the data is in compliance with the conceptual framework. The internal validity of the study was provided in this way. Since the participants in the research were decided to keep their identities ethically confidential, the findings were encoded in the form of flowers 1 , flowers 2 .

\section{Findings and comments}

The analyze of the questions which were asked during the research were handled in this part. There was a common view to the first question of the research which is "What are the problems that school headmasters face when fulfilling the factors of human resources? " Answers like authority trouble, not being fair at the distribution of tasks, the situation that there is no co-operation of job and not obeying the hierarchical order were given:

a. There are problems at governance which headmasters face while fulfilling the factors of the human resources. One of the biggest problems is the situation that, there is no co-operation or there is no common decision. There are troubles at dichotomy and common management by interaction.

b. Not accepting the authority enough and not sharing the duty and responsibilities. Fair task is the situation that there is no job arrangement. 
c. There are minor problems when there is no co-operation. There can be problems at the mismatch between people furthermore the situation that hierarchical order is not obeyed is seen as the complex of problem solving of people who are authorized.

As it can be understood from the answers, there is a situation that, headmasters should make the share of information and should share the authorities and responsibilities equally and when there is a discrimination employee try to not reflect this to job however there are absolutely problems at the job and it is also seen that employee cannot give himself or herself over to the job. There is a common view upon to the second question which is "What are the responsibilities of school headmasters about solving the social and economic problems while fulfilling the factors of human resources? ". There are answers like, solving the problem immediately, inspecting, overcoming the problems in co-operation and sharing the solved problems with the individuals, were given within the scope of answers received from eight participant.

a. Whatever is needed socially and economically when fulfilling the responsibilities should be meet and problems can be destroyed and responsibilities can be distributed with the cooperation

b. School managers should solve the economic and social problems immediately and should have a common communucation between people to solve the problem and should value ideas.

c. Guide and follow the individuals who have a good relationship with the headmaster(inspect), manager should make the responsibilites of him and share these with the people.

As it can be understood from the received answers, every managers should solve the problems by sharing the solving ways and views, by taking support and ideas from the people and should go into solving way by continuing with the received information even if every headmaster try to solve the problem of their own. There are answers like being insistent for the needs, being democtaric,participant and being in a co-operation with employees, being a bridge between staff and not to make discrimination to the third and last question of interview form which is "What kind of management type is adopted by headmasters at fulfilling the factors of human resources? "

A. There should be way of management adopted which is democtaric, participant and includes respect and there is some aberration from this due to personnel relationships.

B. The administration is the factor which is made from authorized employee and which can help to find solution to the problems. The management is related with the fulfilling the factors of the human resources. There should be co-operation and there shouldnt be any discrimination.

C. The headmaster should be insistent and sure about the determined needs and should not stop until he or she realises the desired thing.

The headmaster should always be by teachers and should send teachers to education with the purpose of better teaching and should adopt a management style which there is a co-operation and democracy between administration and employee. As it can be understood from the received answers, headmasters should proceed with the people who, can add information at every topic, who can perform studies about the needs without any retreat, who progress can be made with, and who can renew the teachers and himself or herself about information. ${ }^{17,18}$

\section{Conclusion and suggestions}

The answers that are received from teachers are very close to each other and there are some different answers too, at this study which the views of headmasters for teachers about fulfilling the management and factors of the human resources is received. Headmasters should be together with people who have different economical situation, culture and religion and should develop, activities about these differences. Behaviours, manners, thoughts and ideas at the school will be an important management style at the education institutions and will have a positive effect on the academic or vocational progression of teachers and employees. Positive behaviours which are thought to be gained is not just for the education at the class environment however it should have a big role on the keeping pace with school of teachers, to have a good relationship between teachers and headmasters and behaviours like being more active in the school. It is seen that the existing problems will disappear if headmasters fulfill the factors of human resources in the best way. To prevent the problems which will occur, headmaster should transmit the desicions which are taken by him to teachers. Headmasters should send teachers to seminars, symposiums and to education councils based on curriculum with the purpose of increase the efficiencies of teachers. ${ }^{18-20}$

In this content, the headmaster should in an effort, to improve his or her own curriculum and to improve the success of the school by transmitting information to the school employee. These findings have an important role at the fulfilling of the factors of human resources. Headmaster should evaluate the success of teachers without any discrimination and should take the sufficieny into consideration while giving fair decisions. Headmaster should move without creating competition between teachers and employee, should have transparent management mentality at the implementation of prize and punishment as fair, equal and objective. Headmaster should perform evaluations which is transparent, informative and respectful to the ideas. Headmaster should take the suggestions of teachers while listening to their presentations about this and should apply for the views of teachers with the purpose of achieving the purposes and views of the school and should move commonly at the fulfilling the factors of human resources. Headmaster should consider the purpose and structure of the school as procurser at the movement of school forward. Headmasters should be individuals who have a good leadership qualities, who have communcation and management skills, who can take the good usage of mother language, who have taken history education and who belive to the education. An insight will be provided to the progression of and implementation of deficiencies without deficiency at management of human resources and functions by conducting realistic evaluations and by approaching to the problems at management of human resources and functions. ${ }^{20-23}$

\section{Conclusion}

The roles of headmasters are very significant at the activity and efficiency of education institutions and at the institutions which social and individual importance very significant without discussion. Headmaster should be motivator, should inform employee and teachers at the change of rules and transmit the deficient information by a good way of management. Headmasters should open-minded, should be equal to employees and teachers and should go out of "I" centred management and should pass in to modern management. From the 
expectations of teachers, the role of headmaster is very effective and headmaster should be in a position which, can answer to the desires of teachers without being insusceptible to the environment, should take the deficiencies and economy of the school into consideration, should express the rules that have to be obeyed in the society and should go forward by assuring the administration and education with the cooperation with teachers and with the carefrontation to his or her work.

\section{Acknowledgements}

None.

\section{Conflict of interest}

The authors declare that there is no conflict of interest.

\section{References}

1. Bursalığlu Z. New Structure and Behavior in School Management Ankara, Pegemas Publishing, Turkey; 2008.

2. Faulkenberry TM. A comparison of teachers' perceptions of key instructional leadership behaviors and instructional leadership behaviors identified in effective schools' research. UMI, Bell \& Howell Co. 1996.

3. De Nisi AS, Ricky W Griffin. Human resorce management. houghton mifflin company, New York, USA; 2001.

4. French, Wendell L. Human Resource Management. Oxford University Press, USA; 1998.

5. Fındıkçı İ. Management Human Resources. Alfa Publishing, Istanbul, Turkey; 2000 .

6. Çelik V. School Culture and Management, Pegem Publishing, Ankara, Tukey; 2002.

7. Özgen H, Öztürk, A ve Yalçın A. İnsan Kaynakları Yönetimi, Adana, Nobel Yayın. 2002.

8. Bingöl D. Human Resources Management. Beta Publications, Istanbul, Turkey; 1998.
9. Akalın A vd. Eğitim ve Okul Yöneticiliği El Kitabı, Pegem Yayıncılık, Ankara, Tukey; 2004.

10. Uğur A. İnsan kaynakları yönetimi, Sakarya Kitabevi, Sakarya, Turkey; 2003.

11. Erdoğan İ. School Management Teaching Leadership. Sistem Yayıncılık, İstanbul, Turkey; 2002.

12. Yalçın SA. Personel Yönetimi, Beta Yayınları, İstanbul, Turkey; 2002.

13. Özmen İ. Information Systems Business Strategy and Use to Provide Commercial Advantage, Istanbul University Business Administration Faculty. Institute of Business Economics Journal. 2003;13:45-51.

14. Çelik V. Human Resource Management Approach and its Application to Educational Administration. Dokuz Eylül University Buca Eğitim Fakültesi I. Education Congress. 1991;25(27):200-201.

15. Karasar N. Biilimsel Araştırma Yöntemi, Nobel Yayınları, Ankara, Turkey; 2000.

16. Kozak N. Sosyal Bilimlerde Araştırma Yöntemleri. Anadolu Üniversitei Ders Notları, Eskişehir, Turkey; 2001.

17. Barutçugil I. Stratejik İnsan Kaynakları Yönetimi, Kariyer Yayıncılık, İstanbul Betimleme nedir? Erişim. 2004;26:0402017.

18. Binbaşığlu E. Endüstri Psikolojisi, Kadıoğlu Matbaası, Ankara, Tukey; 1992.

19. Patton MQ. Qualitative research \& evaluation methods. 3rd edn. Thousands Oaks, Sage Publications, Turkey; 2002.

20. Sadullad Ö. Human Resources Management. Beta Basım Yayıncılık, Istanbul, Turkey; 2015.

21. Yönetim nedir? Erişim Tarihi, Turkey.

22. Yönetișim Sorunları ve Sorumlulukları nelerdir? Erișim.

23. Dokuz Eylül University. 